\title{
DESIGNING AND EVALUATING E-MANAGEMENT DECISION TOOLS
}




\section{INTEGRATED SERIES IN INFORMATION SYSTEMS}

Series Editors

Professor Ramesh Sharda

Oklahoma State University

Prof. Dr. Stefan Voß

Universität Hamburg

Other published titles in the series:

E-BUSINESS MANAGEMENT: Integration of Web Technologies with Business Models/ Michael J. Shaw

VIRTUAL CORPORATE UNIVERSITIES: A Matrix of Knowledge and Learning for the New Digital Dawn/Walter R.J. Baets \& Gert Van der Linden

SCALABLE ENTERPRISE SYSTEMS: An Introduction to Recent Advances/ edited by Vittal Prabhu, Soundar Kumara, Manjunath Kamath

LEGAL PROGRAMMING: Legal Compliance for RFID and Software Agent Ecosystems in Retail Processes and Beyond/Brian Subirana and Malcolm Bain

LOGICAL DATA MODELING: What It Is and How To Do It/ Alan Chmura and J. Mark Heumann 


\section{DESIGNING AND EVALUATING E-MANAGEMENT DECISION TOOLS}

The Integration of Decision and Negotiation Models into Internet-Multimedia Technologies

Giampiero E.G. Beroggi

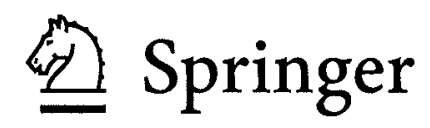


Giampiero E. Beroggi

Zurich School of Business Administration

Zurich, Switzerland

Library of Congress Cataloging-in-Publication Data

A C.I.P. Catalogue record for this book is available from the Library of Congress.

ISBN 0-387-23174-9 e-ISBN 0-387-23175-7 Printed on acid-free paper.

(C) 2005 Springer Science+Business Media, Inc.

All rights reserved. This work may not be translated or copied in whole or in part without the written permission of the publisher (Springer Science + Business Media, Inc., 233 Spring Street, New York, NY 10013, USA), except for brief excerpts in connection with reviews or scholarly analysis. Use in connection with any form of information storage and retrieval, electronic adaptation, computer software, or by similar or dissimilar methodology now know or hereafter developed is forbidden.

The use in this publication of trade names, trademarks, service marks and similar terms, even if the are not identified as such, is not to be taken as an expression of opinion as to whether or not they are subject to proprietary rights.

Printed in the United States of America.

987765543321

SPIN 11323990

springeronline.com 
In memory of my father, my uncle and my friend Manoli 


\section{TABLE OF CONTENTS}

Preface xiii

Acknowledgments $\quad$ XV

\section{CHAPTER 1: DECISION MODELING PARADIGMS}

1. A Taxonomy of Decision Support Environments 1

1.1 Introduction 1

1.2 Problem Solving and Decision Making 2

1.3 Visual Modeling and the Analytic Modeling Process 4

2. Decision Modeling 7

2.1 Structural Models in Decision Analysis $\quad 8$

2.2 Formal Models in Decision Analysis $\quad 11$

2.3 Resolution Models in Decision Analysis $\quad 12$

3. Data/Knowledge Modeling 13

3.1 Structural Models for Data/Knowledge Systems 14

$\begin{array}{ll}\text { 3.1.1 Data Models } & 14\end{array}$

3.1.2 Knowledge Models 16

3.2 Formal Models for Data/Knowledge Systems 17

$\begin{array}{ll}\text { 3.2.1 Data Models } & 17\end{array}$

$\begin{array}{ll}\text { 3.2.2 Knowledge Models } & 18\end{array}$

3.3 Resolution Models for Data/Knowledge Systems 20

3.3.1 Data Models $\quad 20$

3.3.2 Knowledge Models 20

4. Dynamic Modeling $\quad 22$

4.1 Structural Models for Dynamic Systems $\quad 22$

4.2 Formal Models for Dynamic Systems $\quad 24$

4.3 Resolution Models for Dynamic Systems 25

5. Discussion 26

5.1 Synergies and Relations among the Modeling Paradigms 26

5.2 Model Formulation Support Environment 29

$\begin{array}{ll}5.3 \text { Conclusions } & 31\end{array}$ 


\section{CHAPTER 2: VISUAL INTERACTIVE DECISION MODELING}

1. The Concept 33

1.1 Modeling and Problem Solving 33

1.2 The Elements of Decision Modeling $\quad 35$

1.3 Structuring the Decision Problem 37

1.4 Resolution Mapping $\quad 40$

1.5 Conclusions $\quad 42$

2. Case Studies in VIDEMO 43

2.1 Case Study 1: Energy Modeling 43

2.1.1 Liberalization of the Electricity Sector 43

2.1.2 Evaluating Improvements in Electric Utility Reliability 45

2.1.3 Resolution Mapping 46

2.1.4 Formal Modeling, Solution Display, and Decision Making 48

2.1.5 Conclusions $\quad 50$

2.2 Case Study 2: Integrated Safety Management $\quad 50$

2.2.1 Introduction 50

2.2.2 Structural Modeling $\quad 52$

2.2.3 Formal Modeling 54

2.2.4 Resolution Modeling 57

2.2.5 Operationalization of Safety Concept 58

2.2.6 An Illustrative Example $\quad 59$

2.2.7 Conclusions $\quad 62$

2.3 Case Study 3: Water Resource Management 63

2.3.1 Introduction 63

2.3.2 Strategic Analysis $\quad 64$

2.3.3 Tactical Analysis $\quad 65$

2.3.4 Conclusions $\quad 67$

3. A Hypermedia Concept in Education 68

3.1 Introduction 68

3.2 Examples of Models in VIDEMO 70

3.3 VIDEMO as a Structural Modeling Tool $\quad 72$

3.4 VIDEMO as a Decision Support Tool 74

3.5 Conclusions $\quad 75$ 


\section{CHAPTER 3: ONLINE PREFERENCE ELICITATION}

1. Interface Design for Preference Elicitation in Online Environments $\quad 77$

1.1 Introduction $\quad 77$

1.2 Principles of Preference Elicitation in Online Environments 79

1.2.1 Preference Profiling 79

1.2.2 Decision Support Strategies $\quad 79$

1.2.3 Visual Interface $\quad 80$

1.2.4 Analytic Interface $\quad 81$

1.2.5 Summary of Interface Requirements 82

1.3 An Efficient Preference Elicitation Algorithm

for Paired Comparisons $\quad 82$

1.3.1 Inference Mechanism for Paired Comparisons $\quad 82$

1.3.2 Resolution of Inconsistencies $\quad 85$

1.3.3 Efficiency of the Algorithm $\quad 87$

1.4 Computer Implementation $\quad 88$

$\begin{array}{ll}1.5 \text { Conclusions } & 89\end{array}$

2. Experimental Assessment of Preference Elicitation Methods 90

2.1 Introduction 90

2.2 Preference Elicitation Methods $\quad 91$

2.3 Research Hypotheses 93

2.3.1 Hypotheses Referring to the Assessment Strategy 93

2.3.2 Hypotheses Referring to the Axioms of Rationality 95

2.3.3 Hypotheses Referring to Choice 96

2.4 Experimental Design $\quad 98$

2.4.1 The Models 98

2.4.2 The Experimental Sessions $\quad 100$

2.4.3 The Subjects 101

2.5 Results 102

2.5.1 Hypotheses Referring to the Assessment Strategy $\quad 102$

2.5.2 Hypotheses Referring to the Axioms of Rationality 105

2.5.3 Hypotheses Referring to Choice 106

2.6 Discussion and Conclusions 107

\section{CHAPTER 4: COLLABORATIVE DECISION MAKING}

1. Elicitation of Individual and Group Preferences 111

1.1 Introduction

1.2 Interactive Preference Ranking

1.3 Preference Aggregation across Criteria and

Decision Makers

1.4 Conclusions 
2. Experimental Assessment of Group DM Support in E-Commerce 117

2.1 Introduction $\quad 117$

2.2 Theoretical Framework 118

2.2.1 Interactive Individual Decision Making 118

2.2.2 Communication $\quad 120$

2.2.3 Group Consensus Reaching 121

2.3 Research Hypotheses 122

2.3.1 Hypotheses Referring to Individual Choice 123

2.3.2 Hypotheses Referring to Communication 124

2.3.3 Hypotheses Referring to Group Consensus 125

2.4 Experimental Design $\quad 126$

2.4.1 The Decision Task 126

2.4.2 The Decision Models 128

2.4.3 The Subjects 129

2.4.4 Data Collection $\quad 130$

2.5 Results 131

2.5.1 Hypotheses Referring to Individual Choice 132

2.5.2 Hypotheses Referring to Communication 132

2.5.3 Hypotheses Referring to Group Consensus 134

2.5.4 Additional Results 134

2.6 Discussion and Conclusions $\quad 135$

3. Training-Based Evolutionary Multimedia Prototyping 137

3.1 Introduction 135

3.2 Training of the Command Incident Place 139

3.3 Evolutionary Multimedia Prototyping 141

3.4 Analysis $\quad 143$

3.5 Conclusions 145

CHAPTER 5: NEGOTIATION AND CONFLICT RESOLUTION

1. Dynamic Plots in Virtual Negotiations 147

1.1 Introduction and Motivation 147

1.2 Dynamic Plots for $2 \times 2$ Virtual Negotiations 149

1.2.1 Moves and Equilibria 149

1.2.2 Examples of Move Strategies and Negotiation
Settlements in $2 \times 2$ Virtual Negotiations

1.3 Dynamic Plots for $3 \times 3$ Virtual Negotiations $\quad 159$

1.4 Applications 163

1.4.1 Computer Implementation 163

1.4.2 Empirical Evidence $\quad 164$

1.5 Conclusions and Outlook 167 
2. Experimental Assessment of Virtual Negotiations with

Dynamic Plots

2.1 Introduction $\quad 169$

2.2 Two Alternative Negotiation Support Concepts $\quad 170$

2.2.1 Dynamic Plots 170

2.2.2 Numeric Systems 173

2.3 Hypotheses 174

2.4 Experimental Design 177

2.4.1 The Conflict Situations 177

2.4.2 The Subjects and the Performance of the Experiment 179

2.5 Results 180

2.6 Conclusions 183

CHAPTER 6: MARKETING DECISION OP'TIMIZATION

1. Optimizing Direct-Marketing Decisions 185

1.1 Real Options Decision Analysis 187

1.2 The Models 189

1.2.1 Model for "Do not Test" Option 189

1.2.2 Model for "Do Test" Option 190

1.2.3 Model for Risk Attitude $\quad 190$

1.2.4 System Design 193

1.2.5 Case Study 194

$\begin{array}{ll}1.3 \text { Conclusions } & 197\end{array}$

2. Preference Elicitation in Product Design 198

2.1 Conjoint Analysis 199

2.2 Predicting Preferences with Linear Regression 200

2.3 Assessing Tradeoffs 201

2.3.1 Tradeoffs within Attributes 201

2.3.2 Tradeoffs across Attributes 202

2.4 Prototype System in an Internet-Multimedia Environment 203

\section{CHAPTER 7: GUIDELINES FOR DESIGNING AND EVALUATING DECISION TOOLS}

1. Designing Decision Tools in an Internet-Multimedia Environment

1.1 Systems and Technologies 205

1.2 Interactive Web-based Multimedia Systems 206

1.3 Designing Visual Interactive Interfaces 209

1.4 Integrating Analytic Models 210 
1.5 Creating Collaborative Work Environments 212

1.5.1 Multiuser Applications with Multiuser Server $\quad 212$

1.5.2 Multiuser Applications with CGI-Scripts 213

2. Experimental Assessment of Decision Tools 216

2.1 What should be Tested? 216

2.2 Test vs. Truth 218

2.3 Testing Differences in Proportions 220

2.3.1 Testing one Proportion 221

2.3.2 Testing Proportions from two Populations 223

2.3.3 Testing Interactions for Proportions 224

2.4 Testing Differences in Means 226

2.5 Single-Factor ANOVA 227

2.6 Two-Factor ANOVA 229

2.6.1 Two-Factor ANOVA without Replications $\quad 229$

2.6.2 Two-Factor ANOVA with Replications 230

2.7 Experimental Designs 231

2.7.1 Latin Square Designs $\quad 232$

2.7.2 Orthogonal Designs 233

2.7.3 Fractional Factorial Designs 234

2.7.4 Taguchi Designs 234

$\begin{array}{ll}\text { References } & 237\end{array}$

Subject Index 251 


\section{PREFACE}

Decision support entails two aspects: (1) the means to augment sensory perception and (2) the means to augment the cognitive thinking process. Sensory perception is augmented through the use of multimedia technology, while the cognitive thinking process is augmented through the use of analytic and behavioral reasoning models. The integration of these two components into a decision support system is the basis for more efficient and effective decision making.

In order to evaluate an information system's potential, the system must be tested with subjects; i.e., potential future users. Testing can refer to casebased evidence, or, on a more rigorous base, to experimental assessment in a laboratory setting.

Over the past seven years I have designed, developed, and tested several decision support systems. Unlike most other endeavors in this field, I developed these decision support systems in an Internet-multimedia environment, rather than as part of standard analytic software systems. The disadvantage of this approach was that I had to program most of the algorithms myself, rather than building upon algorithms embedded in standard analysis software systems.

Nevertheless, it is my contention that this was the better approach, for the simple reason that sensory perception drives analytic reasoning and not vice versa. Had I chosen to work the other way round, I would not have been able to design the decision support systems to enhance the cognitive thinking process. Instead, I would have, at the very best, only been able to show what the potential and limits of off-the-shelf decision support tools might be.

Many of these systems that are discussed in this book can be downloaded or used on the Internet at:

\section{http://www.beroggi.net}

The different systems discussed in the seven chapters of this book, their design and evaluation, are summarized in the following table. Most of the systems were developed in Oracle Media Object (OMO) and in Macromedia Director, while only a few of them were developed in Delphi Pascal. Systems developed in OMO can be downloaded and used as standalone systems with the OMO player, and systems developed in Delphi can be downloaded and used as standalone executable files. Systems developed in Director have been placed on the Internet and can be used directly on the Internet with the Shockwave player. 


\begin{tabular}{|c|c|c|}
\hline Chapter & Topic & Systems (evaluation) \\
\hline 1 & Modeling environments & - none \\
\hline 2 & VIDEMO & - Videmo.htm (case studies, experim.) \\
\hline 3 & Online preference elicitation & $\begin{array}{l}\text { - Preference.htm (experimental) } \\
\text { - AHP.htm (experimental) }\end{array}$ \\
\hline 4 & $\begin{array}{l}\text { Collaborative decision } \\
\text { making }\end{array}$ & $\begin{array}{l}\text { - Group.htm (case study) } \\
\text { - E-commerce.htm (experimental) }\end{array}$ \\
\hline 5 & $\begin{array}{l}\text { Negotiation and conflict } \\
\text { resolution }\end{array}$ & $\begin{array}{l}\text { - Two_linear.exe (experimental) } \\
\text { - Three_linear.exe } \\
\text { - Two_non_linear.exe }\end{array}$ \\
\hline 6 & $\begin{array}{l}\text { Marketing decision } \\
\text { optimization }\end{array}$ & $\begin{array}{l}\text { - Risk.htm (case study) } \\
\text { - Conjoint.htm (simulation) }\end{array}$ \\
\hline 7 & $\begin{array}{l}\text { Guidelines for design and } \\
\text { evaluation }\end{array}$ & $\begin{array}{l}\text { - FileIO.htm (case study) } \\
\text { - Ranking.htm (case study) }\end{array}$ \\
\hline
\end{tabular}

The organization of the book is illustrated in the figure below. The three most relevant modeling paradigms for decision tools are discussed in Chapter 1. From these three paradigms, the Visual Interactive Decision Modeling (VIDEMO) concept is derived in Chapter 2.

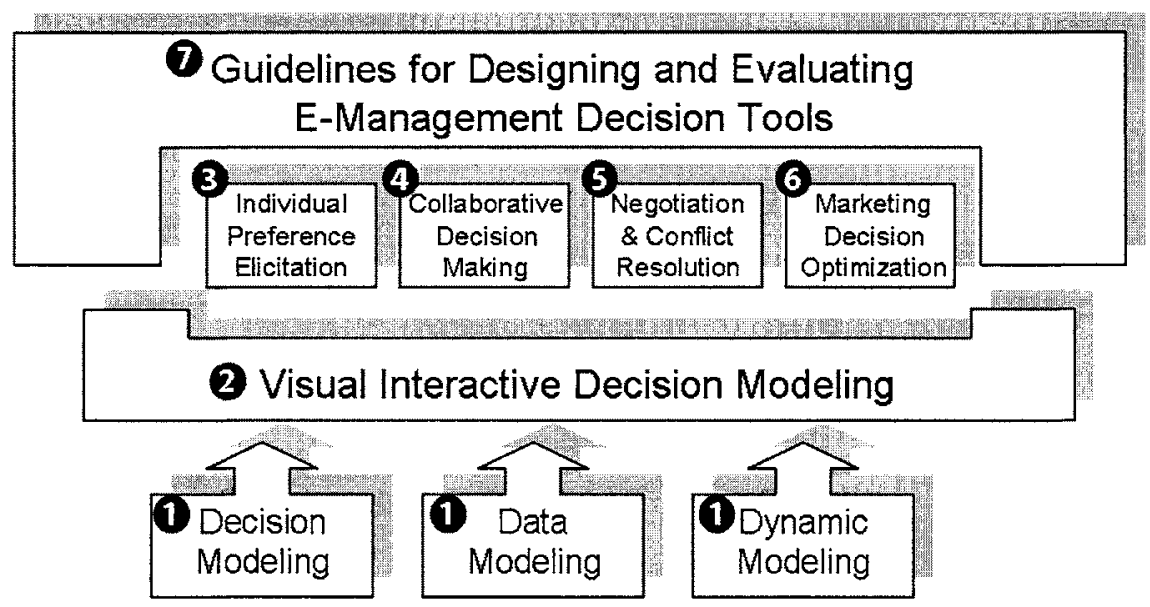

The four chapters (3 to 6) discussing specific aspects of designing and evaluating e-management decision tools are based on the VIDEMO concept. The guidelines for designing and evaluating e-management decision tools are discussed in Chapter 7.

Giampiero E.G. Beroggi Zurich, Switzerland Summer 2004 


\section{Acknowledgements}

This book is a compilation of research that I have conducted over the past seven years. I am most thankful to all the people who have provided reviews, suggestions, and comments that helped improve the quality of the work, including my colleagues, peers, and anonymous reviewers of scholarly journals.

My warmest thank goes to my wife, Penny Spring, for helping and encouraging me during these past years of work in the Netherlands, Finland, Germany and Switzerland. I am also very thankful to her for reviewing and improving selected sections of this book. 